\title{
Cisto aracnóideo intradiploico não traumático - Relato de caso
}

\section{Nontraumatic Intradiploic Arachnoid Cyst - Case report}

\author{
${ }^{1}$ Acadêmico de Medicina da Universidade Cidade de São Paulo, São \\ Paulo, SP, Brasil \\ 2 Médico, Pós-graduando da Faculdade de Medicina de Ribeirão Preto \\ (USP), São Paulo, SP, Brasil; I Tenente Médico Neurocirurgião do \\ Hospital de Aeronáutica de São Paulo (HASP), São Paulo, SP, Brasil \\ ${ }^{3}$ Médico, II Tenente Médico Patologista do HASP, São Paulo, SP, Brasil \\ Arq Bras Neurocir 2015;34:86-90.
}

Carlos Roberto Massella Junior ${ }^{1}$ Marcelo Campos Morares Amato ${ }^{2}$ Marcelo Luiz Balancin ${ }^{3}$
Address for correspondence Carlos Roberto Massella Junior, MD, Rua João Antônio de Oliveira, 1.228, Mooca, São Paulo, SP, Brasil, CEP 0311-001 (e-mail: cr.massellajr@gmail.com).

Universidade Cidade de São Paulo, São Paulo, SP, Brasil e Hospital de Aeronáutica de São Paulo (HASP), São Paulo, SP, Brasil,

\section{Resumo \\ Palavras-Chave \\ - cistos aracnóideos \\ - aracnóideos/ patologia \\ - aracnóideos/ fisiopatologia \\ - aracnóideos/cirurgia \\ - craniotomia}

\section{Abstract}

received

January 1, 2014

accepted

November 1, 2014
Existem apenas 14 casos descritos de cistos aracnóideos intradiploicos sem traumatismo craniano prévio. O objetivo deste estudo é relatar um caso de cistos aracnóideos intradiploicos e alertar para a possibilidade deste diagnóstico entre as lesões osteolíticas do crânio. Um paciente masculino de 74 anos, com histórico de adenocarcinoma de próstata, tratado com radioterapia há 2 anos, realizou tomografia de crânio para investigação de tontura. Esta mostrou lesão lítica de $2 \mathrm{~cm}$ parietoccipital direita. Não havia história de trauma ou alteração neurológica. A ressonância magnética mostrou tecido isointenso ao parênquima cerebral preenchendo a cavidade óssea. O paciente foi submetido à craniectomia ao redor da lesão e foi identificada herniação de tecido encefálico para dentro da díploe craniana. Ao exame anatomopatológico não foram encontradas células neoplásicas, mas sim a presença de cavidade intraóssea com superfície interna recoberta por faixa de tecido conjuntivo fibrilar frouxo e tecido cerebral com morfologia preservada, estabelecendo o diagnóstico de cisto intradiploico com herniação de tecido cerebral. Cistos aracnóideos intradiploicos são geralmente achados incidentais. A cirurgia é necessária para o diagnóstico, mas pode ser evitada em pacientes assintomáticos e quando não há evidência de neoplasia maligna. Portanto, se o tratamento conservador for escolhido, sugere-se seguimento clínico e imagenológico, já que a história natural é desconhecida.

There are only 14 reported cases of intradiploic arachnoid cysts without prior head injury. The aim of this study is to report a case of intradiploic arachnoid cysts. Neurosurgeons must be aware of this possibility among osteolytic lesions of the skull. A male patient, 74 years old, with a history of prostate adenocarcinoma treated with radiotherapy for two years, held cranial tomography for investigation of dizziness. This showed a $2 \mathrm{~cm}$ parietal-occipital osteolytic lesion. There was no history of trauma or neurological disorder. The magnetic resonance imaging showed tissue filling the bone cavity that was isointense to brain parenchyma. The patient underwent craniectomy
DOI http://dx.doi.org/ 10.1055/s-0035-1547375. ISSN 0103-5355.
Copyright $(2015$ by Thieme Publicações License terms Ltda, Rio de Janeiro, Brazil
(®) $\Theta \circledast$ 


\section{Keywords}

- arachnoid cysts

- arachnoid/pathology

- arachnoid/ physiopathology

- craniotomy around the lesion, and brain tissue herniation was identified into the cranial diploe. Histopathology did not demonstrate neoplastic cells; the inner surface of the bone cavity was covered by loose fibrillar connective tissue and brain tissue with preserved morphology, establishing the diagnosis of IAC with brain tissue herniation. Intradiploic arachnoid cysts are usually incidental findings. Surgery is required for diagnosis, but it can be avoided in asymptomatic patients when there is no evidence of malignancy. Therefore, if conservative treatment is chosen, close clinical and imaging follow-up is advised, since IAC natural history is unknown.

\section{Introdução}

Cistos aracnóideos intradiploicos (CAIs) são lesões muito raras, apenas 14 casos sem traumatismo craniano prévio foram descritos na literatura ( - Tabela 1 ). 0 achado de lesão craniana osteolítica em exames de imagem deve incluir como diagnósticos diferenciais, além de CAI, mieloma múltiplo, granuloma eosinofílico, cisto epidermoide, osteomielite e tumores ósseos metastáticos. ${ }^{1}$ Apesar dos CAIs serem geralmente assintomáticos e, portanto, diagnosticados de forma incidental após a realização de exames de neuroimagem como a tomografia computadorizada (TC) e a ressonância nuclear magnética (RNM), o diagnóstico definitivo é realizado através de biópsia. Este procedimento é muitas vezes realizado, apenas para descartar os diagnósticos diferenciais. $^{2}$

O objetivo deste estudo é relatar um caso de CAI e alertar para a possibilidade deste diagnóstico diferencial entre as lesões osteolíticas do crânio.

\section{Relato do Caso}

Um paciente masculino de 74 anos de idade apresentava histórico de adenocarcinoma de próstata e foi tratado com radioterapia 2 anos antes de ser encaminhado ao serviço de neurocirurgia do Hospital de Aeronáutica de São Paulo (HASP). O paciente queixava-se de tontura, não apresentava história de trauma e nem outras queixas neurológicas. 0 exame neurológico foi normal. Devido a sua história oncológica, optou-se pela investigação inicial com TC de crânio que mostrou lesão ovalada lítica de $2 \mathrm{~cm}$ em região parietoccipital direita (-Fig. 1). Posteriormente, foi realizada RNM, que mostrou tecido isointenso ao parênquima cerebral preenchendo a cavidade óssea e com captação de contraste paramagnético nas margens da lesão óssea (-Figs. 2A-D). 0 paciente foi submetido à craniectomia ao redor da lesão, e ao ato cirúrgico foi identificada herniação de tecido encefálico para dentro da díploe craniana. Destaca-se a presença de orifício na dura-máter observado logo após a remoção do flap

Tabela 1 Relação de relato de casos de cisto aracnóideo intradiploico não traumático

\begin{tabular}{|c|c|c|c|c|c|c|}
\hline Autores & Idade & Sexo & Região óssea & Sintomas & Cirurgia & Pós-operatório \\
\hline \multirow[t]{2}{*}{ D́Almeida e King ${ }^{14}$} & 61 & Masculino & Parietal & Não & Sim & Sem intercorrências \\
\hline & 53 & Masculino & Frontal & Não & Sim & Sem intercorrências \\
\hline \multirow[t]{2}{*}{ Weinand et al. ${ }^{13}$} & 70 & Feminino & Occipital & $\operatorname{Sim}$ & Sim & Sem intercorrências \\
\hline & 68 & Feminino & Occipital & Sim & Sim & Sem intercorrências \\
\hline \multirow[t]{5}{*}{ Hasegawa et al. ${ }^{1}$} & 54 & Feminino & Occipital & Não & Sim & Sem intercorrências \\
\hline & 70 & Feminino & Occipital & Não & Sim & Sem intercorrências \\
\hline & 58 & Feminino & Occipital & Não & Sim & Sem intercorrências \\
\hline & 71 & Masculino & Occipital & Não & Sim & Sem intercorrências \\
\hline & 74 & Feminino & Occipital & Não & Sim & Sem intercorrências \\
\hline Alfieri et al. ${ }^{4}$ & 57 & Feminino & Frontal & Sim & Sim & Sem intercorrências \\
\hline Asahi et al. $^{2}$ & 60 & Masculino & Parietal & Não & Sim & Sem intercorrências \\
\hline Krupp et al. ${ }^{15}$ & 30 & Masculino & Frontal & Sim & Sim & Sem intercorrências \\
\hline Yamaguchi et al. ${ }^{12}$ & 72 & Feminino & Occipital & Não & Sim & Sem intercorrências \\
\hline Caso atual & 74 & Masculino & Occipital & Não & Sim & Sem intercorrências \\
\hline
\end{tabular}




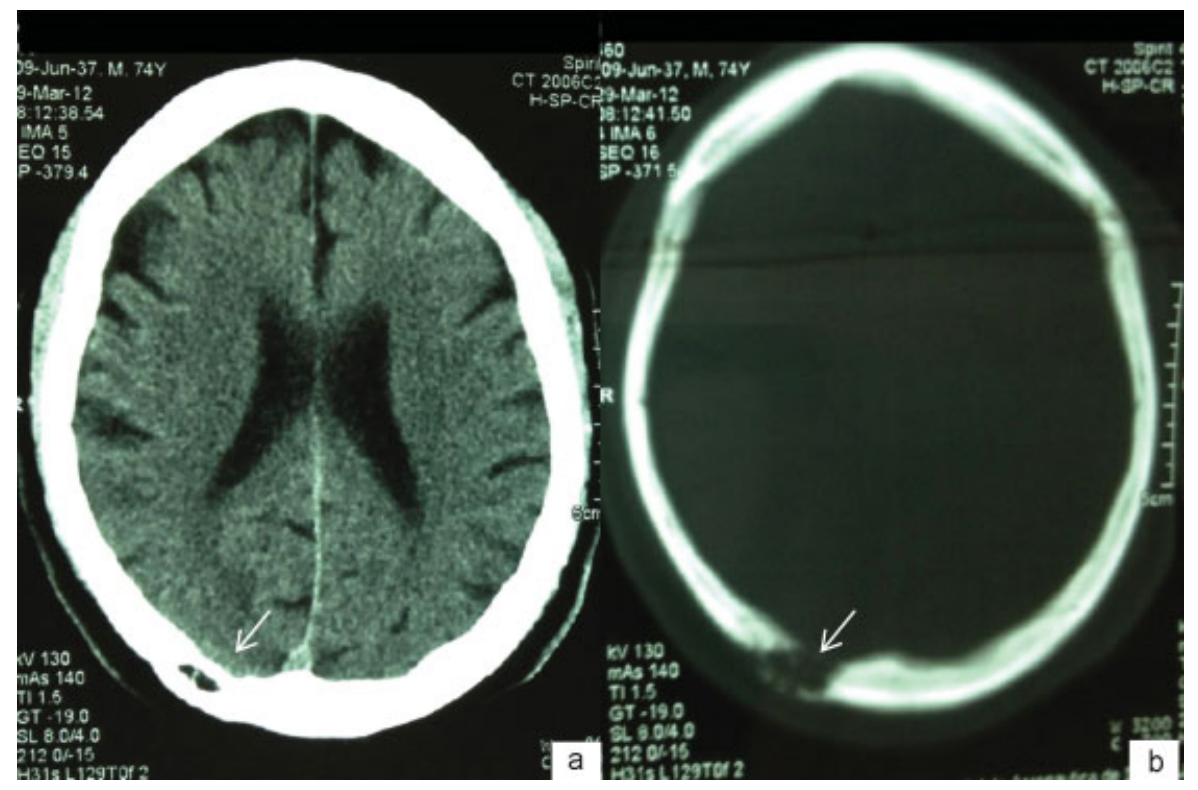

Fig. 1 Cortes axiais de TC mostram erosão óssea em região parietoccipital direita, mais evidente na janela óssea (b). As setas mostram a lesão lítica e o cisto na díploe craniana.

ósseo (-Fig. 2D). Ao exame anatomopatológico não foram encontradas células neoplásicas, mas sim a presença de cavidade intraóssea com superfície interna recoberta por faixa de tecido conjuntivo fibrilar frouxo e tecido cerebral com morfologia preservada, estabelecendo o diagnóstico de CAI com herniação de tecido cerebral (-Fig. $\mathbf{3}$ ).

\section{Discussão}

Os CAIs são raras lesões osteolíticas do crânio, cujas características clinicopatológicas ainda permanecem obscuras. Weinand, em 1988 (apud Asahi et al. ${ }^{2}$ e Iplikcioglu et al. ${ }^{3}$ ), foi o primeiro a propor o termo cisto aracnóideo intradiploico, após relatar dois casos, e até o ano de 2013 foram registrados apenas 14 casos de CAIs não traumáticos, sendo o caso de nosso estudo o $15^{\circ}$ descrito (-Tabela 1 ).

Acredita-se que os CAIs se desenvolvam como divertículos da aracnoide através de pequenos defeitos na duramáter. A pulsação contínua através do defeito causa erosão da tábua interna e, consequentemente, o tecido herniado se expande para dentro do espaço intradiploico, que é menos resistente que as tábuas interna e externa. As fraturas ósseas em crescimento são entidades mais comuns e têm patogenia semelhante, no entanto estas apresentam defeitos adquiridos na dura-máter e no crânio, enquanto os CAIs não traumáticos apresentam defeitos provavelmente congênitos. $^{3-7}$ Cistos espinhais extradurais, também chamados de divertículos durais, apresentam características patogênicas semelhantes, e a etiologia pode ser traumática, inflamatória, iatrogênica e congênita. ${ }^{3,8}$ Da mesma forma, a etiologia é difícil de ser determinada na maioria dos casos de CAIs. ${ }^{4,5}$ Iplikcioglu et al., ${ }^{3}$ por exemplo, acreditam que o caso por eles relatados é secundário a um traumatismo craniano esque- cido pelo paciente. Os CAIs não traumáticos costumam apresentar defeitos ovalados e pequenos na dura-máter, enquanto os casos traumáticos apresentam lesões durais lineares paralelas ao eixo de fratura do crânio, além de ser possível observar fratura da tábua óssea externa e lesões no tecido encefálico.

Para o diagnóstico e o manejo do CAI, é necessário entender sua apresentação clínica, evolução, diagnósticos diferenciais e tratamento cirúrgico. A história natural não é totalmente conhecida e precisa ser melhor estudada. 9,10

Essa doença é caracterizada por clínica assintomática ou inespecífica, como dor local. Assim, os CAIs são geralmente achados incidentais em exames de neuroimagem. As lesões parecem ser lentamente progressivas e podem acometer grandes extensões da díploe craniana. ${ }^{3} \mathrm{Na}$ TC, os CAIs aparecem como lesões osteolíticas, bem demarcadas. Na RNM, essas lesões costumam ser isointensas ao líquor, tanto em T1 como em T2. ${ }^{11}$ No caso apresentado, a RNM mostrou sinal isointenso ao parênquima cerebral, haja vista a presença deste tecido herniado através do defeito dural.

As lesões líticas cranianas podem ter uma variedade de causas, incluindo lesões benignas ou malignas, infecciosas e granulomatosas, tais como tumor ósseo metastático, granuloma eosinofílico, mieloma múltiplo e cisto epidermoide. ${ }^{11}$ O CAI não traumático é uma possibilidade diagnóstica incomum para tais lesões, mas que deve ser considerada especialmente se as outras alternativas forem descartadas. ${ }^{12} \mathrm{O}$ cisto epidermoide pode ser diferenciado do CAI através da sequência de difusão da RNM, na qual aparece com hiperintensidade de sinal, já que tumores costumam apresentar captação de contraste paramagnético na RNM. ${ }^{3}$ 


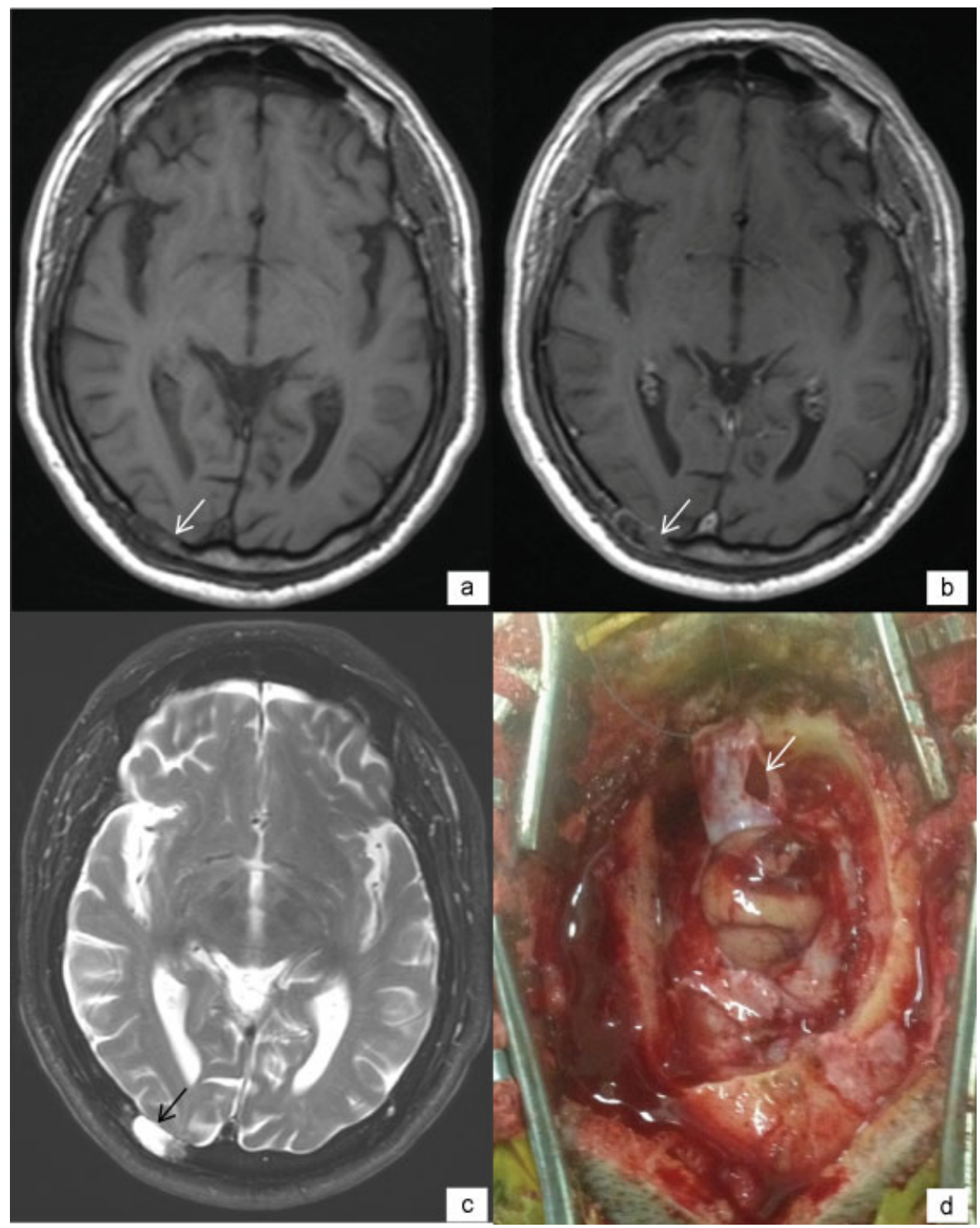

Fig. 2 Cortes axiais de RNM. Na sequência T1, antes (a) e após (b) injeção de gadolínio, a seta mostra tecido isointenso ao parênquima cerebral preenchendo a cavidade óssea, além de captação de contraste paramagnético nas margens do cisto ósseo. A sequência T2 (c) mostra hipersinal na cavidade óssea, compatível com a presença de líquido cefalorraquidiano. Procedimento cirúrgico (d): após craniotomia parietoccipital, notase orifício pequeno e ovalado na dura-máter (seta), através do qual havia tecido encefálico herniado.

O tratamento cirúrgico dos CAIs não traumáticos é simples e geralmente bem sucedido. Deve-se realizar a craniotomia ao redor da lesão, reparar o defeito dural e realizar a cranioplastia em seguida. No entanto, as cirurgias são geralmente necessárias para o diagnóstico histológico e não para o tratamento do cisto. ${ }^{2,3}$

Em nosso paciente, que apresentava história oncológica e possibilidade de metástase, a RNM identificou captação de contraste nas margens da lesão. Ao ato cirúrgico, foi identificada lesão dural pequena e ovalada, erosão da tábua óssea interna e expansão da díploe craniana. A presença de tecido encefálico normal, associada à ausência de células neoplásicas ao exame anatomopatológico, corroborou o diagnóstico de CAI não traumático.
Apesar das dificuldades apresentadas, se o diagnóstico pré-operatório puder ser estabelecido em pacientes assintomáticos e com pequenas lesões, pode-se optar pelo seguimento clínico e radiológico, haja vista a natureza benigna dessas lesões. $^{1-3}$

Os CAIs são geralmente achados incidentais. A investigação, que inclui exames de neuroimagem, é importante especialmente para descartar os diagnósticos diferenciais. A cirurgia é necessária para o diagnóstico definitivo, mas pode ser evitada em pacientes assintomáticos e quando não há evidência de neoplasia maligna. Portanto, se o tratamento conservador for escolhido, sugere-se seguimento clínico e imagenológico, já que a história natural é pouco conhecida. 


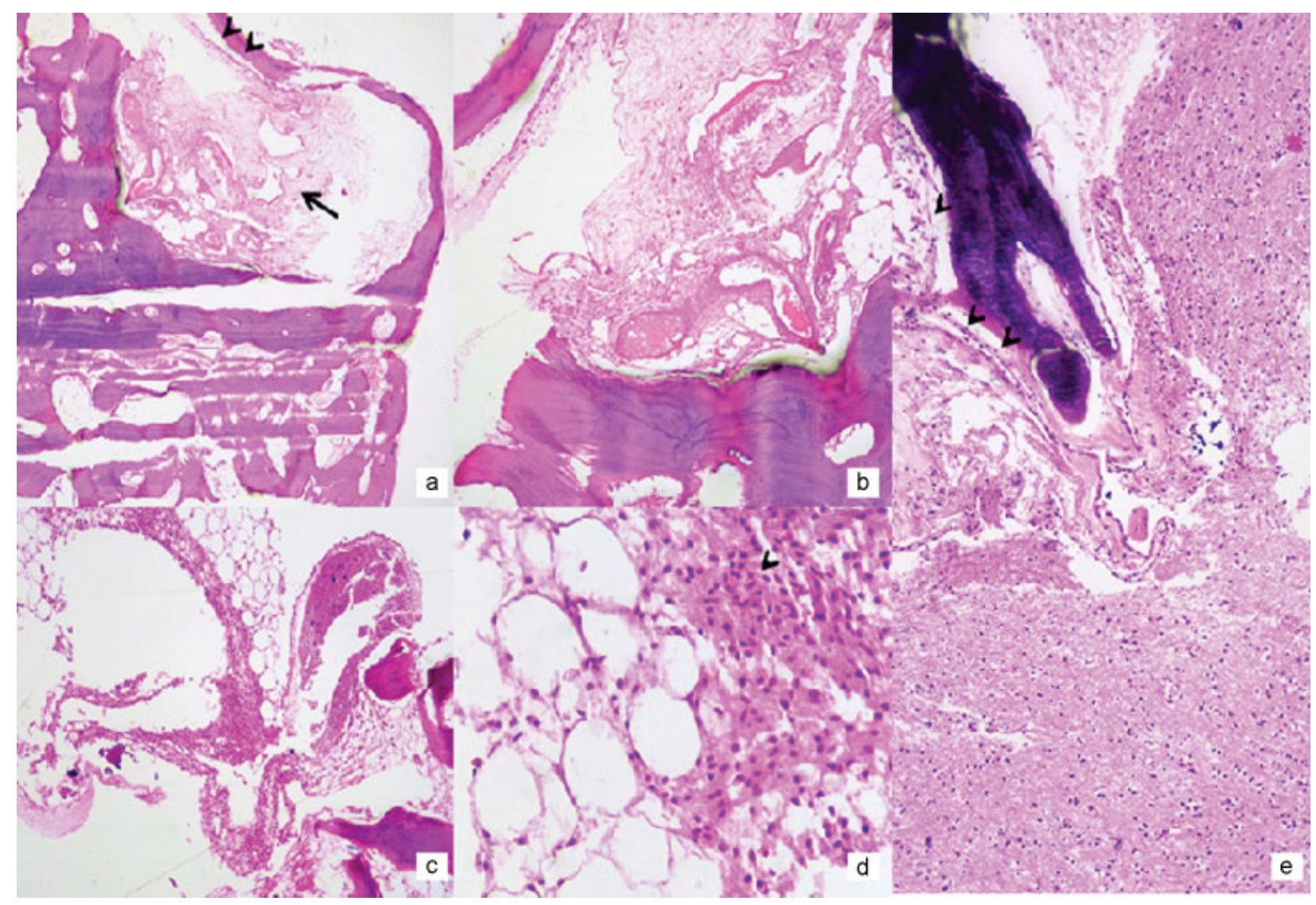

Fig. 3 Fotomicrografia da lesão mostrando: (a) área óssea cística margeada por células meningoteliais (cabeças de setas), associada à neovascularização (seta); (b) em maior aumento, estrita relação das células meningoteliais com a superfície óssea; (c) células meningoteliais epitelioides típicas dispostas em padrão lobular; (d) detalhe citológico das células meningoteliais epitelioides sem atipia, esboçando padrão em espiral; (e) interposição de tecido cerebral à membrana aracnóidea e ao cisto ósseo, evidenciando a natureza cística da lesão (cabeças de setas) (HE, 4x, 10x, 10x, 40x, 4x).

\section{Conflitos de Interesse}

Os autores declaram não haver conflitos de interesse.

\section{Referências}

1 Hasegawa H, Bitoh S, Koshino K, Obashi J, Iwaisako K, Fukushima Y. Nontraumatic intradiploic arachnoid cysts-report of five cases. Neurol Med Chir (Tokyo) 1992;32(12):887-890

2 Asahi T, Endo S, Akai T, Takaba M, Takaku A. Nontraumatic convexity intradiploic arachnoid cyst. Neurol Med Chir (Tokyo) $1998 ; 38(6): 374-376$

3 Iplikcioglu AC, Dinc C, Bikmaz K, Bek S, Gokduman CA, Cosar M. Non-traumatic intradiploic arachnoid cyst. Acta Neurochir (Wien) 2006;148(6):659-662

4 Alfieri A, Zona G, Cirillo S, Spaziante R. Intradiploic arachnoid cyst: case report. Neuroradiology 1996;38(6):569-571

5 Roka YBR, Koirala R. Non-traumatic intradiploic arachnoid cyst of the posterior fossa. Nepal J Neurosci 2010;7(1):31-34

6 Thomas TA, Rout D. Non-traumatic intraosseous cerebrospinal fluid cyst with associated craniovertebral anomalies: a case report and suggested mechanism of formation. Neurol India 2010;58(1):122-124

7 Seo BR, Lee JK, Jeong IH et al. Post-traumatic intradiploic leptomeningeal cyst of the posterior fossa in an adult. J Clin Neurosci 2009;16(10):1367-1369
8 de Oliveira RS, Amato MC, Santos MV, Simão GN, Machado HR. Extradural arachnoid cysts in children. Childs Nerv Syst 2007; 23(11):1233-1238

9 Cilluffo JM, Onofrio BM, Miller RH. The diagnosis and surgical treatment of intracranial arachnoid cysts. Acta Neurochir (Wien) 1983;67(3-4):215-229

10 Castro SC. Cistos aracnóides intracranianos - tratamento pela neuroendoscopia. Arq Neuropsquiatr 1999;57(1):63-67

11 Tsue TT, Stanley RB Jr.. Intradiploic arachnoid cyst presenting as a frontal sinus mass. Otolaryngol Head Neck Surg 1996;114(1): 110-112

12 Yamaguchi S, Hirohata T, Sumida M, Arita K, Kurisu K. Intradiploic arachnoid cyst identified by diffusion-weighted magnetic resonance imaging-case report. Neurol Med Chir (Tokyo) 2002;42(3): 137-139

13 Weinand ME, Rengachary SS, McGregor DH, Watanabe I. Intradiploic arachnoid cysts. Report of two cases. J Neurosurg 1989; 70(6):954-958

14 D'Almeida AC, King RB. Intradiploic cerebrospinal fluid fistula. Report of two cases. J Neurosurg 1981;54(1):84-88

15 Krupp W, Döhnert J, Kellermann S, Seifert V. Intradiploic arachnoid cyst with extensive deformation of craniofacial osseous structures: case report. Neurosurgery 1999;44(4): 868-870 